\title{
The effect of arteriovenous sheathotomy on cystoid macular oedema secondary to branch retinal vein occlusion
}

\author{
M T Cahill, P K Kaiser, J E Sears, S Fekrat
}

Br J Ophthalmol 2003;87:1329-1332

\begin{abstract}
Background: Arteriovenous (AV) sheathotomy, a potential treatment for branch retinal vein occlusion (BVO), surgically separates retinal vessels at an AV crossing. Relief of the aetiological obstruction, with resolution of cystoid macular oedema (CMO), may result in improved visual acuity.

Methods: A retrospective review of consecutive cases of AV sheathotomy for BVO was undertaken. Eyes were categorised as having resolution (group 1), reduction (group 2), or persistence (group 3) of CMO. Intergroup comparisons were made with regard to preoperative, intraoperative, and postoperative parameters. Preoperative and postoperative visual acuities were compared within each group.

Results: Of the 27 eyes identified, eight (29.6\%) had resolution, $14(51.8 \%)$ had reduction, and five $(18.6 \%)$ had persistence of $\mathrm{CMO}$. Median preoperative visual acuity was similar in all groups $(1.0,1.0,1.3$, respectively; $p=0.29)$. Overall median follow up was 12.0 months $(Q 1=12.0$, $\mathrm{Q} 2=22.5$ ). Eyes in group 1 had significantly better median postoperative visual acuity than eyes in groups 2 and 310.6 , $1.0,2.0$ respectively; $p=0.01$ ). A significantly higher proportion of eyes in group 1 had visual acuity improvement compared with eyes in the other groups $187.5 \%$ v $35.7 \%$ and $20.0 \% ; p=0.03$ ). Median postoperative visual acuity was significantly better than median preoperative visual acuity in group 1 eyes only $(p=0.02)$. A higher percentage of group 1 eyes had evidence of postoperative retinal perfusion $183.0 \%$ $v 21.43 \%$ and $40.0 \% ; p=0.16)$. Postoperative retinal detachment occurred in three eyes (11.1\%).

Conclusion: Complete resolution of $\mathrm{CMO}$ after AV sheathotomy occurred in one third of patients, and postoperative vision improved significantly in this group. However, in the majority of cases, despite an improvement in $\mathrm{CMO}$, there was no improvement in vision after $\mathrm{AV}$ sheathotomy.
\end{abstract}

B ranch retinal vein occlusion (BVO) is three times as common as central retinal vein occlusion (CVO) and second only to diabetic retinopathy as the most common retinal vascular cause of visual loss. ${ }^{1}$ Reduced visual acuity associated with BVO may be due to cystoid macular oedema (CMO), macular non-perfusion, vitreous haemorrhage secondary to retinal neovascularisation, and traction retinal detachment. ${ }^{2-5}$ Branch retinal vein occlusion nearly always occurs at an arteriovenous (AV) crossing site, ${ }^{6}$ and the artery lies over the vein in $97 \%$ of AV crossings where BVOs occur. ${ }^{6-12}$ Histologically, the adventitia of the vessels fuse at the AV crossing site, while in some cases, the retinal artery and vein share a common media as they cross. ${ }^{13-16}$

Current treatment options focus on treating visually threatening sequelae of the BVO, such as CMO, retinal neovascularisation, vitreous haemorrhage, and traction retinal detachment. ${ }^{2-5}$ A surgical technique to separate the closely associated vessels at the AV crossing has been developed to treat CMO in an attempt to improve visual acuity. ${ }^{17}$ To date, AV sheathotomy has been reported in over 120 patients, with resolution of CMO and subsequent visual improvement documented in the majority of patients in most studies. ${ }^{17-24}$ We report a retrospective study of 27 consecutive eyes with BVO and CMO that underwent vitrectomy with AV sheathotomy.

\section{METHODS}

After institutional review board approval, a retrospective review of consecutive cases of AV sheathotomy for BVO, performed at Duke University Eye Center and the Cole Eye Institute from January 2000 to April 2002, was undertaken. Inclusion criteria included the presence of a BVO, associated CMO, visual acuity (VA) greater than 0.4 on $\log$ MAR scale, and a visible aetiological AV crossing, with the artery overlying the vein. Exclusion criteria included co-existing eye disease and inability to give informed consent. Preoperative data on patient age, sex, VA in logMAR, lens status, the presence of a posterior vitreous detachment (PVD), and duration of BVO before surgery, calculated as the time from symptom onset to the time of surgery, were recorded. The size of the BVO was calculated using colour fundus photographs and a macular photocoagulation study (MPS) template. ${ }^{25}$ Occlusions greater than 16 MPS disc areas were assigned a value of 16 for statistical analysis. Fluorescein angiograms (FA) were examined to confirm the presence of CMO, identify AV crossings, and exclude neovascularisation. The BVO was classified as perfused, non-perfused, or indeterminate. In some eyes, optical coherence tomography (OCT) was used to quantify the CMO.

Patients underwent pars plana vitrectomy with detachment of the posterior hyaloid if necessary. The artery was separated from the vein using a bent microvitreoretinal (MVR) blade inserted between the vessels. The internal limiting membrane (ILM) was not removed. Using operative notes, the posterior hyaloid was categorised as attached or detached; completion of the AV sheathotomy was categorised as difficult or not difficult; reperfusion of the distal occluded vessel after AV sheathotomy was categorised as observed, not observed, or unrecorded; and details of intraoperative complications and their treatments were noted. Postoperative data on duration of follow up, VA, need for cataract surgery, and postoperative complications were recorded. Comparison of preoperative and postoperative data from clinical notes, OCTs, and FAs were used to determine if CMO was resolved, reduced, or persistent (groups 1-3, respectively), and eyes were categorised into one of these groups. Fluorescein angiograms demonstrated postoperative perfusion status.

Univariate analysis was carried out to determine the significance of associations between groups with regard to the outlined preoperative, intraoperative, and postoperative parameters using Fisher's exact test for categorical variables 
and the Kruskal-Wallace test for continuous variables. If the Kruskal-Wallace test was significant, pairwise comparisons between groups were assessed using the Wilcoxon rank sum test. The Wilcoxin signed rank test was used to determine the significance of any association regarding preoperative and postoperative VA within the groups. Significance was defined as $\mathrm{p}<0.05$.

\section{RESULTS}

Twenty seven eyes of 27 patients underwent vitrectomy with AV sheathotomy. Fourteen (51.8\%) patients were male. Eight (29.6\%) had complete resolution of CMO, 14 (51.8\%) had reduction of $\mathrm{CMO}$, and five ( $18.5 \%$ ) had persistence of CMO. Overall median patient age was 66.7 years $(57.3,77.7)$. Patients in group 1 were younger than those in groups 2 and 3 , although this difference was not significant (Table 1).

The preoperative findings are shown in Table l. The overall median disease duration was 7.0 months $(\mathrm{Ql}=5.5$, $\mathrm{Q} 3=10.0)$ and overall median preoperative VA was 1.0 $(\mathrm{Q} 1=0.9, \mathrm{Q} 3=1.2)$ The median duration of BVO before surgery was shortest in group 3, but this difference was not significant, while the median preoperative VA was similar in each group. An insignificantly higher proportion of eyes in group 1 was phakic compared with other groups. The BVO was located temporally in all eyes, was of similar mean size in all eyes, and similar proportions in each group had a preoperative PVD. The aetiological AV crossing was seen in all eyes and the artery was lying over the vein at all observed crossings. Similar proportions of eyes had angiographic nonperfusion, while extensive intraretinal haemorrhage precluded determination of retinal perfusion in the remaining eyes. There was no evidence of retinal neovascularisation in any eye.

The intraoperative findings are shown in Table 1 . Intraoperative separation of the posterior hyaloid was needed in equal proportions of eyes in all groups. AV sheathotomy was performed with ease in all cases, while reperfusion of the occluded vein occurred in a higher percentage of eyes with CMO resolution. Intraoperative complications included a retinal break in five eyes requiring a scleral buckle in one eye, while the rest were treated with cryotherapy and gas tamponade. There was no statistical difference in the proportion of eyes with intraoperative retinal breaks in any group.

The postoperative findings are shown in Table 1. The overall median duration of follow up was 12.0 months $(\mathrm{Q} 1=12.0, \mathrm{Q} 3=22.5)$. The median duration of follow up was longest in group 3, but this difference was insignificant. Overall median postoperative VA was $0.9 \quad(\mathrm{Ql}=0.5$, Q3 = 1.3), which was not statistically different from the overall median preoperative VA $(p=0.13)$ Median postoperative VA was significantly better, and improved in a significantly higher proportion of eyes in group 1 than in the other groups (Fig 1). There was no significant difference in postoperative VA between groups 2 and $3(\mathrm{p}=0.09)$. The median postoperative VA was significantly better than the median preoperative VA in group 1 only $(p=0.02)$. A higher proportion of eyes had retinal reperfusion in group 1 compared to eyes in other groups. Cataract surgery was performed postoperatively in a significantly higher percentage of eyes with persistent CMO (group 3 ) than in the other groups.

Table 1 Arteriovenous sheathotomy for branch retinal vein occlusion. Demographic, preoperative, intraoperative, and postoperative data

\begin{tabular}{|c|c|c|c|c|}
\hline & Group 1 & Group 2 & Group 3 & \\
\hline & $\begin{array}{l}\text { CMO resolution } \\
(\mathrm{n}=8)\end{array}$ & $\begin{array}{l}\text { CMO reduction } \\
(n=14)\end{array}$ & $\begin{array}{l}\text { CM persistence } \\
(\mathrm{n}=5)\end{array}$ & p value \\
\hline $\begin{array}{l}\text { Demographic data: } \\
\text { Patient age (years) }\end{array}$ & & & & \\
\hline $\begin{array}{l}\text { Median (Q1, Q3) } \\
\text { Preoperative data: }\end{array}$ & $60.8(54.7,68.5)$ & $67.0(61.7,72.5)$ & $61.5(57.3,77.7)$ & 0.56 \\
\hline $\begin{array}{l}\text { Median (Q1, Q3) } \\
\text { VA (log MAR) }\end{array}$ & $7.0(3.7,12.0)$ & $7.5(5.5,11.0)$ & $4.5(3.5,6.6)$ & 0.44 \\
\hline $\begin{array}{l}\text { Median (Q1, Q3) } \\
\text { Phakic eyes }\end{array}$ & $1.0(0.9,1.1)$ & $1.0(0.9,1.2)$ & $1.3(1.0,1.6)$ & 0.47 \\
\hline $\begin{array}{l}\text { Number (\%) } \\
\text { BVO size (MPS DA) }\end{array}$ & $7.0(87.5)$ & $6.0(50.0)$ & $3.0(60.0)$ & 0.15 \\
\hline $\begin{array}{l}\text { Median (Q1, Q3) } \\
\text { Non-perfused BVO }\end{array}$ & $16.0(10.5,16.0)$ & $12.0(12.0,16.0)$ & $12.0(9.0,16.0)$ & 0.80 \\
\hline $\begin{array}{l}\text { Number (\%) } \\
\text { Intraoperative data: }\end{array}$ & $4.0(50.0)$ & $7.0(50.0)$ & $3.0(60.0)$ & 1.00 \\
\hline $\begin{array}{l}\text { Creation of PVD } \\
\text { Number (\%) } \\
\text { Reperfusion of vein }\end{array}$ & $6.0(75.0)$ & $9.0(64.3)$ & $4.0(80.0)$ & 1.00 \\
\hline $\begin{array}{l}\text { Number (\%) } \\
\text { Retinal break identified }\end{array}$ & $3.0(37.5)$ & $3.0(21.4)$ & $1.0(20.0)$ & 0.84 \\
\hline $\begin{array}{l}\text { Number (\%) } \\
\text { Postoperative data: } \\
\text { Follow up (months) }\end{array}$ & $1.0(12.5)$ & $3.0(21.4)$ & $1.0(20.0)$ & 0.87 \\
\hline $\begin{array}{l}\text { Median (Q1, Q3) } \\
\text { VA (log MAR) }\end{array}$ & $11.7(10.0,14.0)$ & $12.0(7.5,14.0)$ & $12.0(12.0,22.5)$ & 0.25 \\
\hline $\begin{array}{l}\text { Median (Q1, Q3) } \\
\text { Improved VA }\end{array}$ & $0.6(0.2,0.7)$ & $1.0(0.5,1.3)$ & $2.0(1.0,2.0)$ & 0.01 \\
\hline $\begin{array}{l}\text { Number (\%) } \\
\text { Retinal perfusion }\end{array}$ & $7.0(87.5)$ & $5.0(35.7)$ & $1.0(20.0)$ & 0.03 \\
\hline $\begin{array}{l}\text { Number (\%) } \\
\text { Cataract surgery }\end{array}$ & $5.0(83.0)$ & $3.0(21.4)$ & $2.0(40.0)$ & 0.16 \\
\hline Number $(\%)$ & $2.0(25.0)$ & $0.0(0.0)$ & $2.0(40.0)$ & 0.05 \\
\hline
\end{tabular}




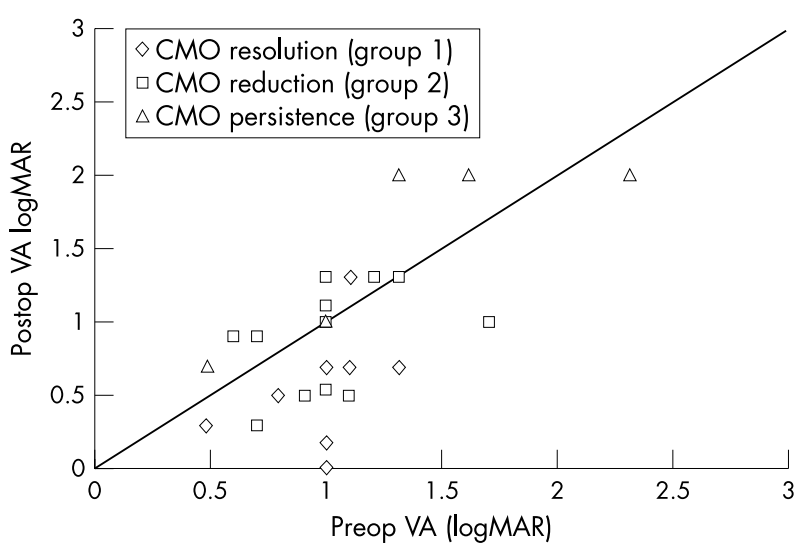

Figure 1 Arteriovenous sheathotomy for branch retinal vein occlusion. Graph plotting preoperative VA against postoperative VA. Data points below, on, and above the line represent eyes with improved, unchanged, and diminished postoperative VA respectively. CMO = cystoid macular oedema.

In group 1, despite resolution of CMO, two eyes had persistent foveal intraretinal haemorrhage, one eye had foveal retinal pigment epithelium (RPE) clumping, and one eye developed an epiretinal membrane. In group 2 , one eye developed a total retinal detachment repaired with a scleral buckle, vitrectomy and intraocular gas tamponade. Another eye in group 2 developed a localised foveal detachment secondary to a retinal break at the AV sheathotomy site, which was treated with vitrectomy, retinopexy, and intraocular gas tamponade. A third eye received $4 \mathrm{mg}$ of intravitreal triamcinolone acetonide 12 months after the sheathotomy with resolution of CMO and visual improvement. A fluocinolone acetonide sustained release device was inserted with resolution of the CMO and VA improvement to $0.3,21$ months after the AV sheathotomy. In group 3, the BVO recurred in two eyes, while a third eye developed a localised foveal detachment secondary to a retinal break at the AV sheathotomy site, which was treated with vitrectomy, retinopexy, and intraocular gas tamponade.

\section{DISCUSSION}

Non-resolution of CMO and the poor visual outcomes reported in this study contrast with reports of CMO resolution and improved VA in most previous studies of $\mathrm{AV}$ sheathotomy. ${ }^{18-24}$ The large size of the BVOs included in this series, and the median disease duration of 7 months, may explain this difference. Although previous AV sheathotomy studies did not determine occlusion size, reported disease durations ranged from 1 to 3 months. ${ }^{18}{ }^{21-24}$ Natural history studies have also demonstrated better visual outcomes in eyes with small BVOs of shorter duration..$^{26-28}$ Alternatively, the poor visual outcomes in our series may be due to the large proportion of eyes with preoperative and postoperative retinal non-perfusion. However, untreated eyes with non-perfused BVO may have better visual outcomes than eyes with intact perifoveal circulation. ${ }^{4}{ }^{28}$ Furthermore, only one previous report of AV sheathotomy has demonstrated improved VA and evidence of retinal reperfusion. ${ }^{22}$ Other reports did not show retinal reperfusion despite improved VA, ${ }^{21} 23$ or documented retinal reperfusion without VA improvement, ${ }^{20}$ or do not adequately comment on postoperative retinal perfusion. ${ }^{18} 1924$

The mechanism by which AV sheathotomy may result in resolution of CMO is unclear. Vitrectomy alone can resolve CMO associated with BVO possibly by removing vitreous traction on the macula or increasing oxygen levels within the inner retina by exposure to oxygenated aqueous. ${ }^{29-31}$ Internal limiting membrane (ILM) removal may also improve CMO secondary to BVO, as evidenced by a previous report of $\mathrm{AV}$ sheathotomy that demonstrated an additional benefit in one third of eyes that also included ILM removal over the macula. ${ }^{21}$ Cutting the common adventitial sheath at AV crossings may relieve pressure exerted by the artery on the vein. ${ }^{17-24}$ However, this relief may only be temporary, as AV sheathotomy does not alter the anatomical relation of the vessels, and leaving the artery resting on the vein may still result in sufficient downward pressure to alter blood flow. Furthermore, the vessels may share a common media at the $\mathrm{AV}$ crossing and cutting this could result in vascular wall damage. ${ }^{16}$

Persistent occlusion or endothelial damage could explain the non-resolution of CMO in most eyes in this study, despite successful intraoperative separation of the vessels. These factors could also explain the postoperative recurrence of $\mathrm{BVO}$ in two eyes in this series. Alternatively, restoration of blood flow may be impossible in eyes with longer duration occlusions similar to those included in this study. Treatments to stabilise or prevent vascular leakage, such as intravitreal steroids, may be an alternative to relieving pressure at the AV crossing, as evidenced by the resolution of CMO seen in one eye only after intravitreal steroid administration. Intravitreal steroid has been reported to resolve retinal oedema in a number of retinal vascular diseases probably by altering endothelial cell tight junctions. ${ }^{32-34}$ Relief of retinal oedema may allow time for a sufficient retinal collateral circulation to develop and steroids may not be needed indefinitely.

Many previous studies report no complications with AV sheathotomy, which may be due to the small number of cases in some of the reports, cases selection, or technical differences. ${ }^{17} 1821-23$ Complications may occur and include recognised vitreous haemorrhage, intraoperative tears, rhegmatogenous retinal detachment, and postoperative cataract. ${ }^{192024}$ Localised retinal detachment originating from the AV sheathotomy site as seen in two eyes in this series has not been reported before. A small retinal break may have been created by one of the sheathotomy instruments at the time of the sheathotomy itself. Other potential complications that may only become apparent with longer follow up include nerve fibre layer defects with associated scotomata, and postoperative epiretinal gliosis with retinal traction.

The limited number of published cases, and the design of available studies of AV sheathotomy, including this present study, limits the conclusions that can be drawn about this treatment. Approximately 120 cases of AV sheathotomy have been reported since the initial case report, ${ }^{17}$ with a variety of study designs using different surgical techniques. Retrospective studies have had conflicting results with improvement in visual acuity in two uncontrolled studies but no improvement in one study that had a control population..$^{19}{ }^{24}$ Three of four previous prospective studies of AV sheathotomy, one of which included a control group, demonstrated improvement in visual acuity in the majority of eyes. ${ }^{21-23}$ However, the fourth study, which was an uncontrolled case series, documented poor visual outcomes in treated eyes. ${ }^{20}$

\section{CONCLUSION}

Arteriovenous sheathotomy did not result in improvement in $\mathrm{VA}$ or in resolution of CMO in most eyes. The mechanism by which AV sheathotomy results in resolution of CMO is unclear and may be caused by other components of the procedure. Arteriovenous sheathotomy may be associated with complications, including retinal detachment. The part that AV sheathotomy plays in the management of eyes with visual loss caused by $\mathrm{CMO}$ associated with BVO requires 
further careful evaluation, as well as comparison with other emerging treatment options, before its widespread acceptance.

\section{Authors' affiliations}

M T Cahill, S Fekrat, Duke University Eye Center, Erwin Road, PO Box 3802, Durham, NC 27710, USA

P K Kaiser, J E Sears, Cole Eye Institute, Cleveland Clinic Foundation, 9500 Euclid Avenue, Cleveland, OH 44195, USA

Correspondence to: Sharon Fekrat, MD, Duke University Eye Center, Erwin Road, PO Box 3802, Durham, NC 27710, USA;

fekra001@mc.duke.edu

Accepted for publication 28 March 2003

\section{REFERENCES}

1 Orth DH, Patz A. Retinal branch vein occlusion. Surv Ophthalmol 1978;22:357-76.

2 Branch Vein Occlusion Study Group. Argon laser photocoagulation for macular edema in branch vein occlusion. Am J Ophthalmol 1984;98:271-82.

3 Branch Vein Occlusion Study Group. Argon laser scatter photocoagulation for prevention of neovascularization and vitreous hemorrhage in branch vein occlusion.

4 Finkelstein D. Ischemic macular edema. Recognition and favorable natural history in branch vein occlusion. Arch Ophthalmol 1992;1 10:1427-34.

5 Ikuno Y, Ikea T, Sato Y, et al. Tractional retinal detachment after branch retinal vein occlusion. Influence of disc neovascularization on the outcome of vitreous surgery. Ophthalmology 1998;105:417-23.

6 Jensen VA. Clinical studies of tributary thrombosis in central retinal vein. Acta Ophthalmol Suppl 1936;10:1-193.

7 Duker JS, Brown GC. Anterior location of the crossing artery in branch retinal vein occlusion. Arch Ophthalmol 1989;107:998-1000.

8 Feist RM, Ticho BH, Shapiro MJ, et al. Branch retinal vein occlusion and quadratic variation in arteriovenous crossings. Am J Ophthalmol 1992;113:664-8

9 Sekimoto M, Hayasaka S, Setogawa T. Type of arteriovenous crossing at site of branch retinal occlusion. Jpn J Ophthalmol 1992;36:192-6.

10 Weinberg D, Dodwell DG, Fern SA. Anatomy of arteriovenous crossing patterns in branch retinal vein occlusion. Am J Ophthalmol 1990; 109:298-302

11 Zhao J, Sastry SM, Sperduto RD, et al. Arteriovenous crossing patterns in branch retinal vein occlusion. The Eye Disease Case-Control Study Group. Ophthalmology 1993;100:423-8.

12 Staurenghi $G$, Lonati $C$, Aschero $M$, et al. Arteriovenous crossing as a risk factor in branch retinal vein occlusion. Am J Ophthalmol 1994;117:211-13.

13 Koyanagi Y. Die bedeutung der gefasskreuzung fur die entstehung der astthrombose der retinalen zentralvene. Klin Monatsbl Augenheilkd 1928:81:219-31.

14 Koyanagi Y. Die pathologische anatomie und pathogenese des kreuzungsphanomens der netzhautgefasse bei hochdruck. Graefes Arch Ophthalmol 1936;135:526-36.
15 Sallmann L. Zur anatomie der gefasskreuzungen am augenhintergrund: zugleich ein beitrag zur pathologischen anatomie des Gunn und Salusschen zeichens. Graefes Arch Ophthalmol 1937;137:619-35.

16 Seitz R. The retinal vessels. Blodi FC, translator, ed. St Louis: CV Mosby, 1964:20-74, 88-94.

17 Osterloh MD, Charles S. Surgical decompression of branch retinal vein occlusions. Arch Ophthalmol 1988;106:1569-71.

18 Brantley MA, Holekamp NM, Shah GK, et al. Increased retinal perfusion after arteriovenous sheathotomy for branch retinal vein occlusion. 105th Annual Meeting of the American Academy of Ophthalmology, New Orleans, 2001.

19 Lee W-H, Thompson JT, Sjaarda RN. Visual acuity results in arteriovenous sheathotomy versus grid laser photocoagulation in branch retinal vein occlusion [ARVO Abstract]. Invest Ophthalmol Vis Sci 2001;42:S718. Abstract no 3862.

20 Le Rouic JF, Bejiani RA, Rumen F, et al. Adventitial sheathotomy for decompression of recent onset branch retinal vein occlusion. Graefes Arch Clin Exp Ophthalmol 2001;239:747-51.

21 Mester U, Dillinger P. Vitrectomy with arteriovenous decompression and internal limiting membrane dissection in branch retinal vein occlusion. Retina 2002;22:740-6.

22 Opremcak EM, Bruce RA. Surgical decompression of branch retinal vein occlusion via arteriovenous crossing sheathotomy: a prospective review of 15 cases. Retina 1999;19:1-5.

23 Opremcak EM, Bruce RA. AV crossing sheathotomy for BRVO (RVS-BVO) [ARVO Abstract]. Invest Ophthalmol Vis Sci 2001;42:S718. Abstract no 3861

24 Shah GK, Sharma S, Fineman MS, et al. Arteriovenous adventitia sheathotomy for the treatment of macular edema associated with branch retinal vein occlusion. Am J Ophthalmol 2000;129:104-6.

25 Macular Photocoagulation Study Group. Laser photocoagulation of subfoveal neovascularization in age-related macular degeneration. Results of a randomized clinical trial. Arch Ophthalmol 1991;109:1220-31.

26 Clemett RS, Kohner EM, Hamilton AM. The visual prognosis in retinal branch vein occlusion. Trans Ophthalmol Soc UK 1973;93:523-35.

27 Michels RG, Gass JD. The natural course of retinal branch vein obstruction. Trans Am Acad Ophthalmol Otolaryngol 1974;78:166-77.

28 Parodi MB, Saviano S, Ravalico G. Grid laser treatment in macular branch retinal vein occlusion. Graefes Arch Clin Exp Ophthalmol 1999;237:1024-7.

29 Kurimoto M, Takagi H, Suzuma K, et al. Vitrectomy for macular edema secondary to retinal vein occlusion; evaluation by retinal thickness analyzer. Jpn J Ophthalmol 1999;53:717-20.

30 Tachi N, Hashimoto Y, Ogino N. Vitrectomy for macular edema combined with retinal vein occlusion. Doc Ophthalmol 1999.97:465-9.

31 Saika S, Tanaka T, Miyamoto T, et al. Surgical posterior vitreous detachment combined with gas/air tamponade for treating macular edema associated with branch retinal vein occlusion: retinal tomography and visual outcome. Graefes Arch Clin Exp Ophthalmol 2001;239:729-32.

32 Martidis A, Duker JS, Greenberg PB, et al. Intravitreal triamcinolone for refractory diabetic macular edema. Ophthalmology 2002;109:920-7.

33 Greenberg PB, Martidis A, Rogers $\mathrm{AH}$, et al. Intravitreal triamcinolone acetonide for macular oedema due to central retinal vein occlusion. Br J Ophthalmol 2002;86:247-8.

34 Gardner TW, Antonetti DA, Barber AJ, et al. Diabetic retinopathy: more than meets the eye. Surv Ophthalmol 2002;47:S253-62. 